\title{
Prevention of complement-induced pulmonary hypertension and improvement of right ventricular function by selective thromboxane receptor antagonism
}

The effect of complement activation on the pulmonary vascular system and on right ventricular function was studied in sheep $(n=12)$ by injection of cobra venom factor. Animals were instrumented for measurement of pulmonary flow, mean pulmonary artery pressure, right ventricular stroke work, arterial blood gases, and systemic vascular resistance. Blood was sampled from the left atrium and pulmonary artery to measure thromboxane $B_{2}$, the metabolite of thromboxane $A_{2}$, by radioimmunoassay. After baseline measurements, animals were randomly assigned to receive a selective thromboxane receptor antagonist $S Q 30741$ as a $10 \mathrm{mg} / \mathrm{kg}$ bolus with an infusion of $10 \mathrm{mg} / \mathrm{kg}$ per hour or else to receive vehicle. Cobra venom factor was then injected $(30 \mathrm{U} / \mathrm{kg})$ in all animals, and data were recorded at 15, 30, 60, 90, and 120 minutes. In control animals there was a 2.4-fold increase in mean pulmonary artery pressure and a $76 \%$ increase in right ventricular stroke work at 15 minutes from baseline $(p<0.05)$; these values remained elevated for 30 minutes and returned to baseline by 1 hour with no change in systemic vascular resistance. Arterial oxygenation decreased by $124 \%$ at 15 minutes and remained depressed through the experiment, but in treated animals oxygen tension remained unchanged from baseline. Thromboxane $B_{2}$ increased $95 \%$ from baseline in the control group and 1.5 fold in treated animals and followed a similar time course as the functional measurements $(p<0.05)$. A pulmonary vascular thromboxane $B_{2}$ gradient of approximately $1000 \mathrm{pg} / \mathrm{ml}$ was measured at 15 and 30 minutes in both control and treated groups. $(p<0.05)$ We conclude that after complement activation in this model pulmonary hypertension and decreased oxygen tension are mediated by thromboxane release from the pulmonary vascular bed. This increased afterload causes a stress on the right ventricle as demonstrated by the increased right ventricular stroke work. Selective thromboxane receptor antagonism may be a beneficial therapy for pulmonary hypertension in patients after cardiopulmonary bypass. (J Thorac Cardiovasc Surg 1994;107:800-6)

Wendel J. Smith, MD (by invitation), Michael P. Murphy, MD (by invitation), Robert F. Appleyard, PhD (by invitation), Robert J. Rizzo, MD (by invitation), Lishan Aklog, MD (by invitation), Rita G. Laurence, BS (by invitation), and Lawrence H. Cohn, MD, Boston, Mass.

D espite advances in myocardial preservation and postoperative management, pulmonary hypertension remains

From the Division of Cardiac Surgery, Brigham and Women's Hospital, The Department of Surgery, Harvard Medical School, Boston, Mass.

Read at the Seventy-third Annual Meeting of The American Association for Thoracic Surgery, Chicago Illinois, April 25-28, 1993.

Address for reprints: Lawrence H. Cohn, MD, Brigham and Women's Hospital, 75 Francis St., Boston, MA 02115.

Copyright $\odot 1994$ by Mosby-Year Book, Inc.

$0022-5223 / 94 \$ 3.00+0 \quad 12 / 6 / 52229$

800 an important determinant of outcome after cardiac transplantation and mitral valve replacement..$^{1-4}$ The cause of acute right ventricular (RV) failure is most often the result of coupling the RV to an increased afterload from pulmonary hypertension, especially when it is not adapted to high pulmonary vascular resistance or when the $\mathrm{RV}$ has poor contractile reserve after prolonged preservation or arrest during cardiopulmonary bypass. ${ }^{5}$ Pulmonary hypertension with RV failure resulting from excessive alteration of pulmonary vascular resistance occurs as one of the effects of cardiopulmonary bypass. ${ }^{6,7}$ 
This acute reactive pulmonary hypertension may not respond to standard pulmonary vasodilator therapy but has been treated with prostacyclin or prostaglandin $E_{1}$ and left atrial phenylephrine (Neo-Synephrine) infusion. These results, however, are compromised by a concomitant reduction in systemic vascular resistance. . $^{8-12}$

After cardiopulmonary bypass, activation of complement and the production of thromboxane $B_{2}$ have been demonstrated in patients and in animal models. ${ }^{13-16}$ Exposure of the pulmonary vascular system to complement-activated serum has been demonstrated to produce pulmonary hypertension, hypoxia, and leukostasis. ${ }^{17,} 18$ In these studies, the pulmonary vascular and hypoxic responses were attenuated by pretreatment with cyclooxygenase synthetase inhibitors. Because thromboxane is a potent vasoconstrictor, we hypothesize that increased thromboxane production is a consequence of complement activation, causing acute pulmonary hypertension and hypoxia and compromised RV function. To test this hypothesis, we used a selective thromboxane receptor antagonist, SQ30741, in an animal model of complement-induced pulmonary hypertension by infusion of cobra venom factor $(\mathrm{CVF})$.

\section{Methods}

Animal preparation. Adult Suffolk sheep weighing 30 to 35 $\mathrm{kg}$ were anesthetized intravenously with thiopental sodium (Pentothal) $15 \mathrm{mg} / \mathrm{kg}$ and their lungs were mechanically ventilated at a tidal volume of $15 \mathrm{ml} / \mathrm{kg}$ with an inspired oxygen fraction of $90 \%$. A central venous catheter was placed percutaneously into the internal jugular vein, and the femoral artery was cannulated for arterial blood gas and pressure measurements. Maintenance anesthesia was controlled by intermittent administration of intravenous thiopental sodium ( 3 to $5 \mathrm{mg} / \mathrm{kg}$ ). All animals received care in compliance with the "Principles of Laboratory Animal Care" formulated by the National Society for Medical Research and the "Guide for the Care and Use of Laboratory Animals" prepared by the National Academy of Sciences and published by the National Institutes of Health (NIH Publication No. 86-23, revised 1985).

The chest was opened via a median sternotomy and an electromagnetic flow probe (Carolina Medical Electronics, Inc., King, N.C.) was placed around the proximal pulmonary artery. Catheter-tipped high-fidelity micromanometers (Millar Instruments, Inc., Houston, Tex.) were introduced into the RV and left ventricular (LV) cavities and into the pulmonary artery. Piezoelectric crystals were tunneled into the septum, sutured to the RV epicardium, and connected to a sonomicrometer (Triton Technology, Inc., San Diego, Calif.) to measure RV septal free wall diameter. A volume conductance catheter (Webster Labs, Inc., Baldwin Park, Calif.) was introduced via the internal carotid artery, guided through the aortic root into the LV, and connected to a Leycom Sigma 5 DF signal processing unit (Cardiodynamics, Rijnsburg, The Netherlands). A vascular catheter was placed into the left atrium to sample blood and to monitor pressure. Physiologic data that were measured included heart rate, femoral artery pressure, pulmonary flow, pulmo- nary pressure, LV pressure and volume, RV septal free wall diameter, RV pressure, and arterial blood gases.

Experimental protocol. After instrumentation, baseline physiologic measurements were recorded and blood samples were collected. Animals were randomized into two groups $(n=6)$ to receive either a selective thromboxane endoperoxide receptor antagonist, SQ30741 (Squibb Pharmaceuticals, Princeton, N.J.), or vehicle. The SQ30741 was prepared in a basic solution of $1 \mathrm{~N}$ sodium hydroxide and titrated to a $\mathrm{pH}$ of 7.4 with an intravenous bolus of $10 \mathrm{mg} / \mathrm{kg}$ given over 3 minutes followed by an infusion of $10 \mathrm{mg} / \mathrm{kg}$ per minute. ${ }^{19}$ All animals were then given CVF $30 \mathrm{U} / \mathrm{kg}$ (Naje Haje; Diamedix, Miami, Fla.) intravenously to produce a model of acute pulmonary hypertension. CVF is a known activator of complement in sheep, and prior studies have documented dosing and activation of the complement system from $\mathrm{CH}_{50}$ assay. ${ }^{20}$ Data were recorded and samples collected at $15,30,60,90$, and 180 minutes after CVF injection.

Assays. Blood samples were collected simultaneously from the pulmonary artery and the left atrium in cold syringes containing aspirin and ethylenediaminetetraacetic acid and centrifuged at $2000 \mathrm{rpm}$ for 15 minutes. The serum was withdrawn and placed in polyethylene tubes, stored at $-90^{\circ} \mathrm{C}$, and later thawed and analyzed for thromboxane $\mathrm{A}_{2}$ with radioimmunoassay by detection of its metabolite thromboxane $B_{2}$. At the termination of the experiment a $5 \mathrm{gm}$ section of the right lower lobe was collected, stored in a polystyrene tube at $-90^{\circ} \mathrm{C}$, and later assayed for myeloperoxidase. ${ }^{21,22}$

Data analysis. Results were summarized and compared by two-way analysis of variance with repeated measures applied to the time measurements. Least-squares estimated mean values generated by this two-way model are presented along with their standard errors. Differences were considered significant when $p<0.05$. When either factor in the two-way model was significant, multiple comparisons were conducted by the StudentNewman-Keuls test. ${ }^{23}$

\section{Results}

Hemodynamic values comparing control animals and animals treated with SQ30741 are summarized in Table I. After injection of CVF there was a significant rise from baseline in pulmonary vascular resistance, mean pulmonary artery pressure, and RV stroke work in all control animals. These values peaked at 15 minutes (Fig. 1, $A$ ), gradually began to decline at 30 minutes, and reached baseline again by 1 hour. Although not reaching statistical significance, an associated drop in pulmonary flow of $10 \%$ occurred at 15 minutes and a $20 \%$ decrease at 30 minutes. In animals receiving SQ30741 these changes were effectively prevented inasmuch as values from 15 to 120 minutes were not significantly changed from baseline (Fig. 1,B). Left atrial pressure was 0 to $1 \mathrm{~mm} \mathrm{Hg}$ in both groups throughout the experiment.

Thromboxane $B_{2}$ levels increased in both control and treated groups (Table II) after a time course that paralleled the increase in pulmonary vascular resistance (Fig. $1, A)$. A significant thromboxane $\mathrm{B}_{2}$ gradient was measured across the pulmonary vascular bed (left atrial-pulmonary arterial values) during the increased pulmonary 
Table I. Hemodynamic measurements

\begin{tabular}{|c|c|c|c|c|c|c|}
\hline & Baseline & $15 \mathrm{~min}$ & $30 \mathrm{~min}$ & $60 \mathrm{~min}$ & $90 \mathrm{~min}$ & $120 \min$ \\
\hline \multicolumn{7}{|c|}{ PVR (dynes $\cdot \mathrm{sec} \cdot \mathrm{cm}^{-5}$ ) } \\
\hline Control & $430 \pm 109$ & $1030 \pm 101^{*}$ & $912 \pm 101^{*}$ & $562 \pm 101$ & $505 \pm 101$ & $442 \pm 101$ \\
\hline SQ30741 & $351 \pm 101$ & $299 \pm 101$ & $268 \pm 101$ & $290 \pm 101$ & $386 \pm 101$ & $395 \pm 101$ \\
\hline \multicolumn{7}{|c|}{ MPAP (mm Hg) } \\
\hline Control & $8.2 \pm 1.7$ & $19.4 \pm 1.6^{*}$ & $17.8 \pm 1.6^{*}$ & $10.1 \pm 1.6$ & $9.2 \pm 1.6$ & $9.4 \pm 1.6$ \\
\hline SQ30741 & $10.1 \pm 1.6$ & $8.6 \pm 1.6$ & $8.0 \pm 1.6$ & $7.5 \pm 1.6$ & $8.2 \pm 1.6$ & $9.2 \pm 1.6$ \\
\hline \multicolumn{7}{|c|}{$\mathrm{QPa}(\mathrm{ml} / \mathrm{min})$} \\
\hline Control & $33.9 \pm 4.8$ & $29.6 \pm 4.6$ & $27.2 \pm 4.6$ & $25.3 \pm 4.6$ & $26.4 \pm 4.6$ & $28.0 \pm 4.6$ \\
\hline SQ30741 & $37.4 \pm 4.6$ & $40.4 \pm 4.6$ & $39.6 \pm 4.6$ & $35.4 \pm 4.6$ & $28.5 \pm 4.6$ & $30.9 \pm 4.6$ \\
\hline \multicolumn{7}{|c|}{ RVSW (dynes $\cdot \mathrm{cm}$ ) } \\
\hline Control & $266 \pm 74$ & $467 \pm 70^{*}$ & $417 \pm 70^{*}$ & $230 \pm 70$ & $233 \pm 70$ & $256 \pm 70$ \\
\hline SQ30741 & $349 \pm 70$ & $328 \pm 71$ & $302 \pm 70$ & $285 \pm 70$ & $262 \pm 70$ & $301 \pm 70$ \\
\hline \multicolumn{7}{|c|}{$\mathrm{RV} \mathrm{dp} / \mathrm{dt}(\mathrm{mm} / \mathrm{sec})$} \\
\hline Control & $401 \pm 75$ & $600 \pm 70$ & $627 \pm 70$ & $445 \pm 69$ & $415 \pm 70$ & $402 \pm 70$ \\
\hline SQ30741 & $790 \pm 69$ & $677 \pm 75$ & $626 \pm 82$ & $509 \pm 75$ & $536 \pm 83$ & $545 \pm 70$ \\
\hline \multicolumn{7}{|c|}{$\mathrm{LV} \mathrm{dp} / \mathrm{dt}(\mathrm{mm} / \mathrm{sec})$} \\
\hline Control & $1815 \pm 234$ & $1684 \pm 222$ & $1469 \pm 222$ & $1517 \pm 222$ & $1474 \pm 222$ & $1569 \pm 222$ \\
\hline SQ30741 & $1697 \pm 199$ & $1700 \pm 208$ & $1552 \pm 221$ & $1267 \pm 207$ & $1437 \pm 221$ & $1552 \pm 199$ \\
\hline \multicolumn{7}{|c|}{ LVSW (dynes $\cdot \mathrm{cm}$ ) } \\
\hline Control & $1097 \pm 446$ & $955 \pm 545$ & $580 \pm 185$ & $610 \pm 320$ & $740 \pm 420$ & $899 \pm 448$ \\
\hline SQ30741 & $1656 \pm 1010$ & $1976 \pm 1492$ & $1356 \pm 1095$ & $1194 \pm 971$ & $1309 \pm 842$ & $1172 \pm 371$ \\
\hline \multicolumn{7}{|c|}{ SVR (dynes $\cdot \mathrm{sec} \cdot \mathrm{cm}^{-5}$ ) } \\
\hline Control & $3019 \pm 608$ & $3140 \pm 608$ & $3513 \pm 606$ & $4300 \pm 606$ & $3785 \pm 527$ & $3678 \pm 527$ \\
\hline SQ30741 & $2711 \pm 408$ & $2420 \pm 493$ & $2605 \pm 493$ & $1871 \pm 495^{*}$ & $2303 \pm 495$ & $3172 \pm 408$ \\
\hline \multicolumn{7}{|c|}{ HR (beats $/ \mathrm{sec}$ ) } \\
\hline Control & $113 \pm 14$ & $116 \pm 13$ & $112 \pm 10$ & $113 \pm 12$ & $110 \pm 14$ & $107 \pm 7$ \\
\hline SQ30741 & $110 \pm 9$ & $103 \pm 5$ & $103 \pm 9$ & $95 \pm 8$ & $100 \pm 11$ & $98 \pm 6$ \\
\hline
\end{tabular}

Values are mean \pm standard error. $P V R$, Pulmonary vascular resistance; $M P A P$, mean pulmonary artery pressure; $Q P a$, pulmonary flow; $R V S W$, right ven tricular stroke work; $R V d p / d t$, right ventricular pressure rate change; $L V d p / d t$, left ventricular pressure rate change; $L V S W$, left ventricular stroke work; $S V R$, systemic vascular resistance; $H R$, heart rate;

$p<0.05$ compared with baseline.

Table II. Peripheral oxygen tension and serum thromboxane values

\begin{tabular}{cccccc}
\hline & Baseline & $15 \mathrm{~min}$ & $30 \mathrm{~min}$ & $60 \mathrm{~min}$ & $120 \mathrm{~min}$ \\
\hline $\mathrm{Po}_{2}(\mathrm{~mm} \mathrm{Hg})$ & & & & & \\
$\mathrm{C}$ & $433 \pm 32$ & $193 \pm 79$ & $168 \pm 64$ & $206 \pm 30$ & $236 \pm 28$ \\
$\mathrm{SQ30741}$ & $494 \pm 68$ & $505 \pm 62$ & $496 \pm 68$ & $556 \pm 44$ & $509 \pm 60$ \\
$\mathrm{TXB}(\mathrm{pg} / \mathrm{ml})$ & & & & \\
$\mathrm{PA}$ control & $1728 \pm 406$ & $2824 \pm 406$ & $2392 \pm 406$ & $2025 \pm 406$ & $1930 \pm 406$ \\
$\mathrm{LA} \mathrm{control}$ & $1877 \pm 442$ & $3588 \pm 442$ & $3187 \pm 442$ & $2130 \pm 442$ & $1891 \pm 442$ \\
$\mathrm{TXB}(\mathrm{pg} / \mathrm{ml})$ & & & & \\
$\mathrm{PA} \mathrm{SQ30741}$ & $2087 \pm 406$ & $3781 \pm 406$ & $5695 \pm 406$ & $3194 \pm 406$ & $2920 \pm 406$ \\
$\mathrm{LA} \mathrm{SQ30741}$ & $2033 \pm 442$ & $5175 \pm 442$ & $6638 \pm 442$ & $3079 \pm 442$ & $2778 \pm 442$ \\
\hline
\end{tabular}

Values are mean \pm standard error. $P O_{2}$, Peripheral arterial oxygen tension; $T X B_{2}$ thromboxane $\mathrm{B}_{2} ; L A$, left atrium; $P A$, pulmonary artery.

vasoconstriction, but thromboxane levels returned to baseline levels by 1 hour (Fig. 2). Arterial blood gas measurements demonstrate a persistent decrease in the oxygen tension at 15 minutes (Table II); by contrast, in the SQ30741 group, values remained near baseline levels (Fig. 1, $A$, and $B$ ) Systemic $\mathrm{pH}$ was maintained between 7.40 and 7.50 throughout the experiment by adjusting respiratory rate Analysis of lung tissue with myeloperoxidase (units per milliliter per gram) showed no significant difference between the two groups (control $=0.26 \pm$ 0.022 ; SQ30741 $=0.22 \pm 0.205$ ).

\section{Discussion}

Our results demonstrate that after complement activation a transitory increase in mean pulmonary artery pressure, pulmonary vascular resistance, and RV stroke work occurs in association with hypoxia. These increases are completely prevented by prior administration of a 

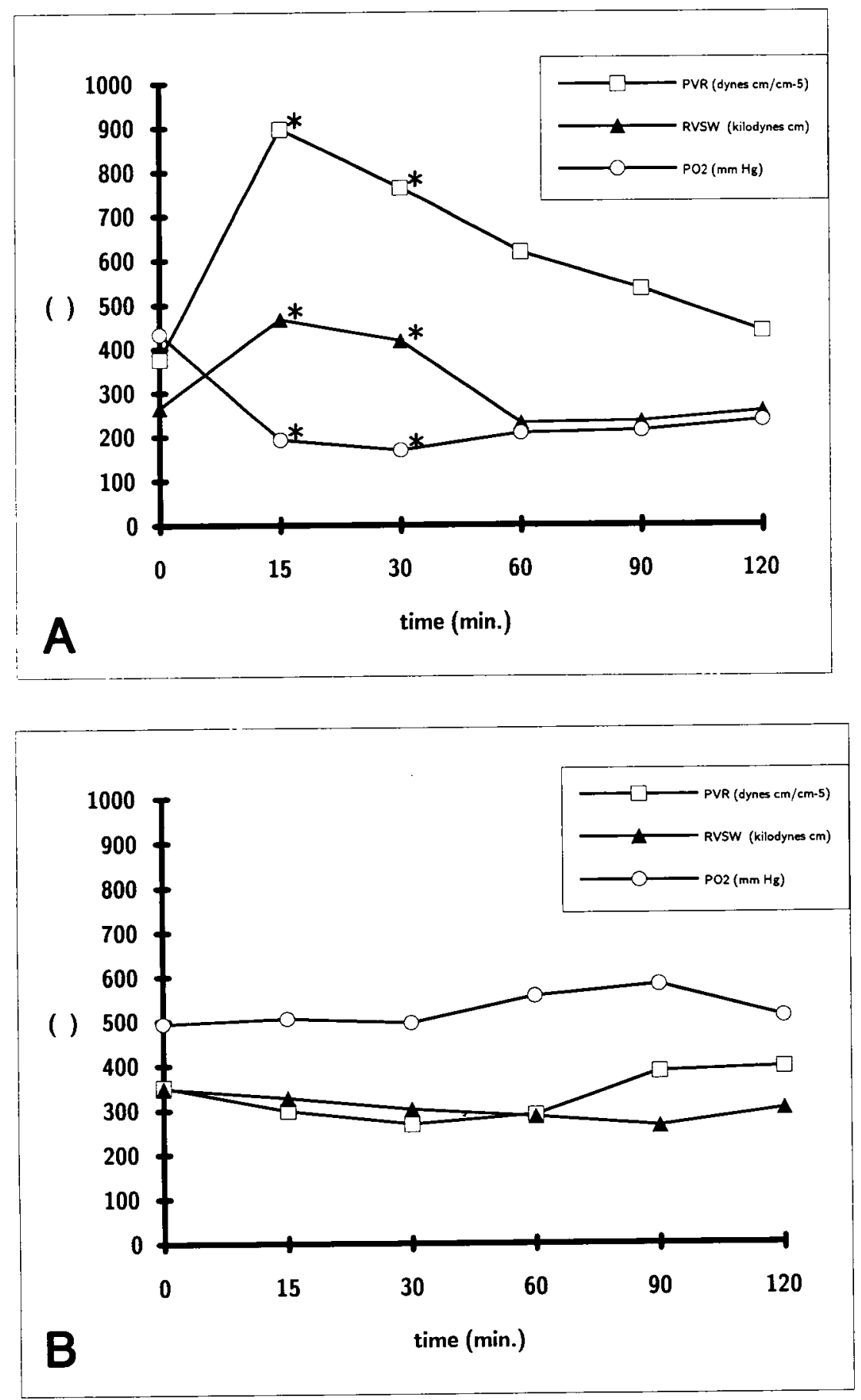

Fig. 1. Time course of pulmonary vascular resistance $(P V R)$, right ventricular stroke work ( $R V S W)$, and arterial oxygenation (PO2) in control animals (A) and in SQ30741-treated animals (B) after injection of CVF at time 0. ${ }^{*} p<0.05$ as compared with baseline.

selective thromboxane receptor antagonist, SQ30741. Substantial production of thromboxane $B_{2}$ occurs across the pulmonary vascular bed, which parallels the physiologic changes and suggests that a significant por- tion of the thromboxane $B_{2}$ may be produced by the pulmonary system. The complete prevention of these effects with thromboxane receptor antagonism indicates that pulmonary hypertension and hypoxia after 


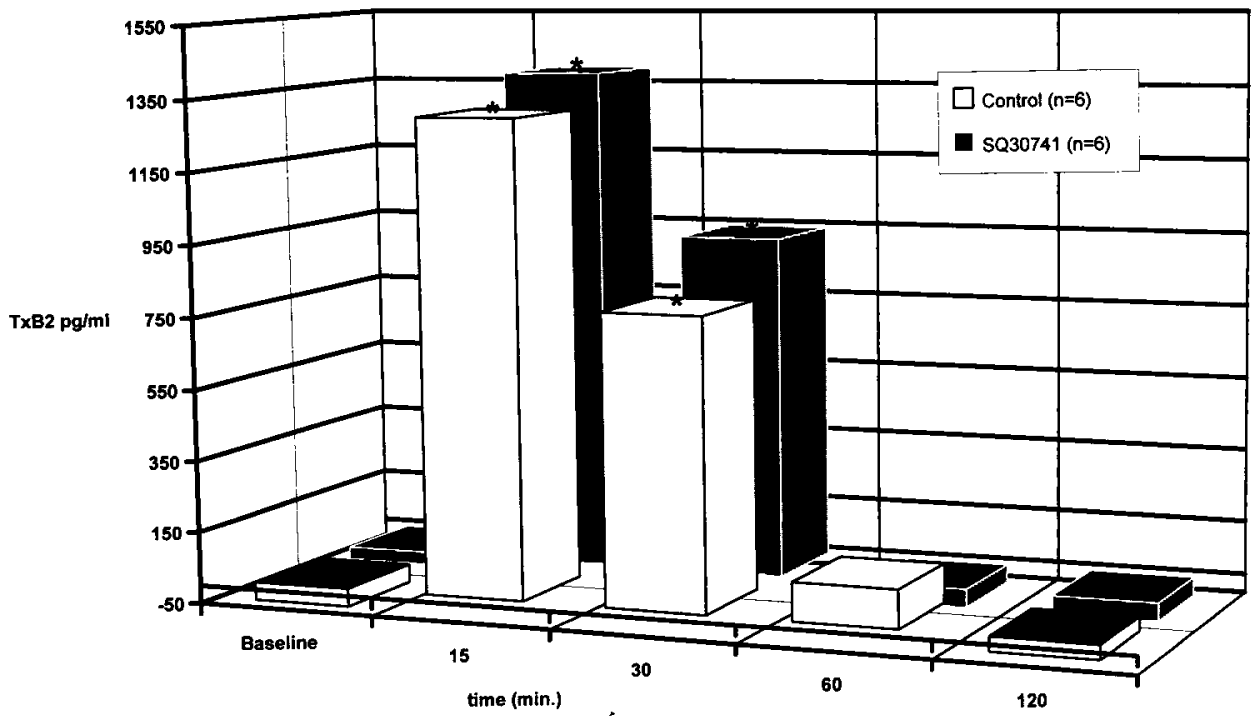

Fig. 2. Pulmonary vascular thromboxane $B_{2}$ gradient as calculated by subtraction of pulmonary artery values from left atrial values after CVF $(30 \mu / \mathrm{kg})$ injection at baseline. ${ }^{*} p<0.05$ as compared with baseline.

complement activation are mediated by thromboxane.

These results confirm prior studies that have shown similar changes in pulmonary pressure and oxygenation to systemic complement activation or infusion of zymozan-activated plasma. ${ }^{24-26}$ Administration of cyclooxygenase synthetase inhibitors before infusion of zymozan-activated plasma has shown variable reductions in mean pulmonary artery pressure depending on the agent used. ${ }^{19,27,28}$ These reductions are probably the result of the nonspecificity of cyclooxygenase inhibition as an agent, but by using a selective receptor antagonist as a tool, we are able to determine more precisely the effects of thromboxane $B_{2}$.

In this model, the pulmonary vasculature responds to thromboxane by vasoconstriction, which increases pulmonary vascular resistance. Because these hearts had normal function before CVF injection, the control group was able to compensate for the increased afterload by increasing stroke work. It is probable that in a heart with poor reserve function or that had undergone a significant stress, such as cardioplegic arrest, the RV would not be able to compensate for the increased afterload and would fail.

The significant increase in the serum levels of thromboxane $\mathrm{B}_{2}$ and development of a pulmonary vascular gradient suggest production within the pulmonary bed. Several authors have noted similar thromboxane $\mathrm{B}_{2}$ gradients across the pulmonary vascular bed after complement activation and have concluded that the main source of thromboxane is the pulmonary system. ${ }^{24,25}$ Perkowski and associates ${ }^{18}$ have suggested that the source of thromboxane is lung endothelial or parenchymal cells, alveolar macrophages, or sequestered polymorphonuclear cells. In our results, SQ30741-treated animals had much higher serum thromboxane $B_{2}$ levels than control animals, although a similar left atrial-pulmonary arterial gradient was seen. One explanation may be that because receptor antagonism prevented the end organ response, a positive feedback loop was established that led to increased production. Another possible explanation is that because the receptor sites were nearly completely saturated, circulating serum levels increased.

The decrease in arterial oxygen tension was prevented in SQ30741-treated animals and appears to be primarily mediated by thromboxane. The mechanism of the decrease in arterial oxygen tension is probably related to the pulmonary vasoconstrictive effects of thromboxane producing pulmonary shunting and not to endothelial vascular damage. Although mild pulmonary endothelial injury has been observed after intravenous injection of zymozan-activated plasma, several authors have noted only mild changes in pulmonary lymph flow and changes in vascular permeability in short-term exposure to complement fragments. ${ }^{20,27,28}$

One limitation of this study is that we were not able to measure the degree of complement activation in the two animal groups. However, complement activation has been assessed in a prior study using CVF in sheep, in which a higher dose $(200 \mathrm{U} / \mathrm{kg})$ was used with the goal to deplete the animals of complement. ${ }^{20} \mathrm{We}$ used a lower dose because patients' systems are not depleted of com- 
plement from cardiopulmonary bypass but are at a lower level of activation.

Treatment of reactive postoperative pulmonary hypertension has consisted primarily of vasodilators, but because of their nonspecificity their effect on the peripheral vasculature limits their use. Use of prostaglandin $E_{1}$ and prostacyclin in these patients causes significant peripheral vasodilation, which sometimes requires the concurrent use of phenylephrine. Our results indicate that thromboxane receptor blockade with SQ30741 did not affect systemic vascular resistance. Prostacyclin and thromboxane have antagonizing actions and their balance may play a significant role in the modulation of pulmonary vascular tone. ${ }^{30}$ It is possible that part of the effect of prostacyclin use in these patients may be the result of its effect on thromboxane metabolism or limiting the thromboxane-induced vasconstriction effect by competitive inhibition.

Thromboxane receptor antagonism may be a useful therapy for reactive postoperative pulmonary hypertension and its detrimental effects on the RV and arterial oxygenation. This is a potentially useful adjunct to other vasodilatory therapy because it allows lower dosing with reduced systemic side effects.

We gratefully acknowledge the assistance of Cindy Barlow, Annie Peimer (Brigham and Women's Hospital), and Dr. Martin Ogletree (Squibb Pharmaceuticals), for without them this project would not have been possible.

\section{REFERENCES}

1. Kirklin JK, Naftel DC, Kirklin JW, Blackstone EH, White-Williams C, Bourge RC. Pulmonary vascular resistance and the risk of heart transplantation. $J$ Heart Transplant 1988;7:331-6.

2. Erickson KW, Costanzo-Nordin MR, O'Sullivan EJ. Influence of preoperative transpulmonary gradient on late mortality after orthotopic heart transplantation. J Heart Transplant 1990;9:526-37.

3. Fragomeni LS, Kaye MP. The registry of the International Society for heart transplantation: fifth official report1988. J Heart Transplant 1988;7:249-53.

4. D'Ambra MN, LaRaia PJ, Philbin DM, Watkins WD, Hilgenberg $A D$, Buckley $M J$. Prostaglandin $E_{1}$ : a new therapy for refractory right heart failure and pulmonary hypertension after mitral valve replacement. J THORAC CARDIOVASC SURG 1985;89:567-72.

5. Page RD, Harringer W, Hodakowski GT, et al. Determinants of maximal right ventricular function. J Heart Lung Transplant 1992;11:90-8.

6. Utley JR. Pathophysiology of cardiopulmonary bypass: current issues. J Cardiac Surg 1990;5:177-89.

7. Nyhan DP, Redmond JM, Gillinov AM, Nishiwaki K, Murrary PA. Pulmonary vasoconstriction is transient but vascular reactivity is increased in conscious dogs following closed-chest hypothermic cardiopulmonary bypass. Circulation 1991;84(Suppl):II2409.

8. Fonger JD, Borkon AM, Baumgartner WA, Achuff SC, Augustine S, Reitz BA. Acute right ventricular failure following heart transplantation: improvement with prostaglandin $\mathrm{E}_{1}$ and right ventricular assist. J Heart Transplant 1986;5:317-21.

9. Pascual JM, Fiorelli AI, Bellotti GM, Groppo NE, Jatene AD. Prostacyclin in the management of pulmonary hypertension after heart transplantation. J Heart Transplant 1990;9:644-51.

10. Vincent JL, Carlier E, Pinsky MR, et al. Prostaglandin $E_{1}$ infusion for right ventricular failure after cardiac transplantation. J THORAC CARdiovasC SuRG 1992;103:33-9.

11. Esmore DS, Spratt PM, Branch JM, et al. Right ventricular assist and prostacyclin infusion for allograft failure in the presence of high pulmonary vascular resistance. $J$ Heart Transplant 1990;9:136-41.

12. D'Ambra MN, LaRaia PJ, Philbin DM, Watkins WD, Hilgenberg AD, Buckley MJ. Prostaglandin $E_{1}$ : a new therapy for refractory right heart failure and pulmonary hypertension after mitral valve replacement. J THORAC CARDIOVASC SURG 1985;89:567-72.

13. Chenoweth DE, Cooper SW, Hugli TE, Stewart RW, Blackstone EH, Kirklin JW. Complement activation during cardiopulmonary bypass: evidence for generation of C3a and C5a anaphylatoxins. N Engl J Med 1981;304:497503.

14. Watkins WD, Peterson MB, Kong Dl, et al. Thromboxane and prostacyclin changes during cardiopulmonary bypass with and without pulsatile flow. J THORAC CARDIOvaSC SURG 1982;84:250-6.

15. Kirklin JK, Westaby S, Blackstone EH, Kirklin JW, Chenoweth DE, Pacifico AD. Complement and the damaging effects of cardiopulmonary bypass. J THORAC CARDIOVASC SURG 1983;86:845-57.

16. Kobina GS, LaRaia PJ, D'Ambra MN, et al. Effect of experimental cardiopulmonary bypass on systemic and transcardiac thromboxane $B_{2}$ levels. J THORAC CARDIOVASC SURG 1986;91:852-7.

17. Cooper JD, McDonald WD, Ali M, Menkes E, Masterson J, Klement P. Prostaglandin production associated with the pulmonary vascular response to complement activation. Surgery 1980;88:215-21.

18. Perkowski SZ, Havill AM, Flynn JT, Gee MH. Role of intrapulmonary release of eicosanoids and superoxide anion as mediators of pulmonary dysfunction and endothelial injury in sheep with intermittent complement activation. Circ Res 1983;53:574-85.

19. Montalescot G, Lowenstein E, Ogletree ML, et al. Thromboxane receptor blockade prevents pulmonary hypertension induced by heparin-protamine reactions in awake sheep. Circulation 1990;82:1765-77.

20. Johnson A, Blumenstock FA, Hussain M, Malik AB. Differential effects of complement activation induced by cobra venom factor on pulmonary transvascular fluid and protein exchange. Am J Pathol 1984;1 14:410-7. 
21. Suzuki K, Sasagawa S, Sakatani T, Fujikura T. Assay method for myeloperoxidase in human polymorphonuclear leukocytes. Anal Biochem 1983;132:345-52.

22. Schierwagen $C$, Bylund-Feleenius AC, Lundberg C. Improved method for quantification of tissue PMN accumulation measured by the myeloperoxidase activity. J Pharmacol Methods 1990;23:179-86.

23. Glantz SA, Slinker BK. Primer of applied regression and analysis of variance. New York: McGraw-Hill, 1990:40431.

24. Peterson MB, Huttemeier PC, Zapol WM, Martin EG, Watkins WD. Thromboxane mediates acute pulmonary hypertension in sheep extracorpeal perfusion. Am J Physiol 1982;243:H471-9.

25. Fountain SW, Martin BA, Musclow CE, Cooper JD. Pulmonary leukostasis and its relationship to pulmonary dysfunction in sheep and rabbits. Circ Res 1980;46:175-80.

26. Gee MH, Perkowski SZ, Tahamont MV, Flynn JT. Arachidonate cycloxygenase metabolites as mediators of complement-initiated lung injury. FASEB J 1985;44:4652.

27. Meyrick BO, Brigham KL. The effect of a single infusion of zymosan-activated plasma on the pulmonary microcirculation of sheep. Am J Pathol 1984;114:32-45.

28. Morganroth ML, Till GO, Schoeneich S, Ward PA. Eicosanoids are involved in the permeability changes but not the pulmonary hypertension after systemic activation of complement. Lab Invest 1988;58:316-23.

29. Till GO, Johnson KJ, Ward PA. Intravascular activation of complement and acute lung injury: dependency on neutrophils and toxic oxygen metabolites. J Clin Invest 1982; 69:1126-35.

30. Christman BW, McPheson CD, Newman JH, et al. An imbalance between the excretion of thromboxane and prostacyclin metabolites in pulmonary hypertension. $\mathrm{N}$ Engl J Med 1992;327:70-5.

\section{Discussion}

Dr. Eric Mendeloff (St. Louis, Mo.). We presented similar data at the American College of Surgery meeting back in 1990 using a similar thromboxane receptor antagonist. We used a somewhat different model of pulmonary hypertension-protamine-induced reversal of heparin after bypass. We also induced a global ischemic injury with bypass. Our findings corroborated yours and we found that the thromboxane receptor antagonist, when given as a bolus after bypass, prevented the protamine reaction. We also found that with continuous infusion the global ischemic injury to the heart was also abolished.

Questions for you: Did you measure LV function and LV end-diastolic pressure? Do you think that impairment of LV function had any effect on the rise in pulmonary artery pressures? Did you measure myocardial oxygen consumption?

Dr. L. Henry Edmunds, Jr. (Philadelphia, Pa.). As far as I know, complement does not activate platelets to synthesize thromboxane $A_{2}$, which is measured as $B_{2}$, so I have no quibble with your results. I would be careful about ascribing thromboxane production to complement activation.

Dr. Smith. Dr. Mendeloff, we used CVF for this model and not cardiopulmonary bypass because we wanted to selectively look at complement-induced pulmonary hypertension without the multiple inflammatory products produced by cardiopulmonary bypass that have many systemic effects. We measured LV stroke work, LV end-diastolic pressure, and left atrial pressure in both groups, and we observed no statistically significant changes. The only physiologic effect produced by the CVF that we measured was an increase in pulmonary vascular resistance.

Dr. Edmunds, certainly the exact source of thromboxane production is not entirely known. In sheep, the platelets have been demonstrated not to produce thromboxane when stimulated in vitro. In our model the thromboxane is probably produced from the pulmonary vascular bed either from macrophages or from the leukocytes that are trapped in the lung tissue as a result of complement activation. 